\title{
SEPAKBOLA SEBAGAI MEDIA SOLIDARITAS POLITIK BAGI SUPPORTER INDONESIA
}

\author{
Kiki Esa Perdana \\ School of management and Leadership, Tanri Abeng University \\ email : kikiesaperdana@gmail.com
}

\begin{abstract}
So far football has not only functioned as a sport but also as a medium of solidarity for supporters, Indonesia is a country with the largest Islamic religion in the world. While many other Islamic countries are still struggling with the problem of war, football believe, its is able to be a medium a solidarity. Message for the victims of war, prayers and solidarity messages are sent through. This research uses descriptive analysis with case studies of Rohingya and Palestinian cases in Indonesian football supporter. This research concludes that the message conveyed by Indonesian supporters. The conclusion, football is possible in becoming tools for political solidarity
\end{abstract}

Keywords: Football, Solidarity

\begin{abstract}
Abstrak
Selama ini sepakbola tidak hanya berfungsi sebagai olahraga namun juga sebagai media solidaritas untuk suporter, Indonesia adalah salah satu negara dengan pemeluk agama islam terbesar di dunia, banyak negara islam lainnya masih berjibaku dengan masalah perang. Sepakbola dalam hal ini mampu menjadi media penghantar bagi para korban perang, ucapan doa dan solidaritas dikirim melalui pesan dalam sepakbola. Riset ini menggunakan analisis deskriptif dengan studi kasus kasus rohingya dan palestina. Riset ini menyimpulkan bahwa pesan yang disampaikan suporter Indonesia, ikut dalam solidaritas secara umum yang dilakukan bangsa Indonesia, feedback yang didapatkan oleh penduduk rohingnya dan palestina positif, terlihat dari poto gambar-gambar ucapan terima kasih pada negara dan masyarakat Indonesia.
\end{abstract}

Kata Kunci: Sepak bola, Solidaritas 


\section{PENDAHULUAN}

Media yang selama ini dikenal khalayak hanya terbatas pada artian sebuah benda atau alat yang menyebarkan informasi,seperti contohnya surat kabar, televisi, radio, atau majalah. Sebenarnya artian media sendiri sangat luas, dalam Buku Pengantar Ilmu Komunikasi (Cangara, 2006:119), media adalah alat atau sarana yang digunakan untuk menyampaikan pesan dari komunikator kepada khalayak, sedangkan artian lainnya menurut Arsyad (2002:4) menyebutkan media adalah semua bentuk perantara yang digunakan oleh manusia untuk menyampaikan atau menyebar ide, gagasan atau pendapat, sehingga ide, gagasan atau pendapat yang dikemukakan itu sampai kepada penerima yang dituju. Media sendiri menurut KBBI, bisa pula diartikan sebagai "yang terletak di antara dua pihak" dan juga"perantara atau penghubung" (https://kbbi.web.id/media).Dengan berbagai difinisi mengenai media tersebut, bisa dipastikan pengertian media tidak hanya terbatas berupa benda atau alat saja.

Sepakbola sendiri merupakan olahraga yang sangat popular di Indonesia, semua orang memainkan sepakbola, mulai dari anak kecil hingga orang dewasa.Kompetisi resmi sepakbola di Indonesia yang diadakan PSSI pun sudah dimulai sejak tahun 1930, ditambah kemudian tahun 1979 dengan kompetisi tambahan dengan nama liga sepakbola utama (Galatama) yang menhadirkan kompetisi klub sepakbola semiprofesional di Indonesia. Liga professional yang sudah menyatukan liga perserikatan dan galatama, sudah dimulai sejak tahun 1993, masih berlangsung hingga sekarang.

Liga Indonesia tahun 2017, adalah salah satu kompetisi yang melibatkan dana yang cukup besar dengan sponsor utama Gojek dan Traveloka, dengan nominal sponsor sebanyak 180 Miliyar rupiah (https://sport.detik.com/sepakbola/ligaindonesia/3470537/ketum-pssi-ungkap-nilaisponsor-gojek-dan-traveloka-di-liga-1).

Menurut data terbukti hingga pekan ke-17, bulan juli, bulan ke lima dalam pertandingan di Liga 1, sudah menyedot perhatian para penonton sebanyak 1,2 juta orang, dengan data penonton terbanyak dicatat pada pertandingan antara Persib Bandung lawan Arema Malang di stadion Bandung lautan Api dengan jumlah penonton 34,150 orang(http://bola.okezone.com/read/2017/07/ 25/49/1743647/menarik-perhatian-pencintasepakbola-nasional-ini-tim-liga-1-denganpenonton-terbanyak).

Dengan sumber daya potensial yang begitu besar tersebut, banyak yang tertarik menjadikan sepakbola sebagai media atau perantara beragam pesan dan informasi, mulai dari perannya sebagai medium bisnis hingga medium politik. Komunikator bisa siapapun 
dalam arena sepakbola, baik tim sepakbola itu sendiri, supporter, atau bahkan orang lain diluar sepakbola yang membutuhkan sepakbola sebagai media sebagi sarana menyampaikan pesan atau informasi.

Kasus Rohingya, kasus Palestina dan kasus pengungsi Suriah adalah sebuah contoh yang mana merupakan tragedi kemanusiaan yang mengusik banyak masyarakat, tidak hanya mereka yang berada di kawasan ASEAN dan Timur Tengah, tetapi juga melintasi belahan bumi di Asia Tenggara, termasuk Indonesia. Media cetak, media elektronik, media cyber, hadir menjadi perantara penyampai informasi dan menyebarkan pesan tersebut ke seluruh belahan dunia hingga banyak orang bisa mengkonsumsi. Feedback yang didapatkan dari fenomena ini salah satunya adalah munculnya rasa solidaritas untuk saling membantu dan rasa peduli yang bermunculan untuk tragedi kemanusiaan tersebut.

Supoorter Indonesia melihat hal tersebut dengan rasa peduli, saat sepakbola mampu menjadi media dan mampu menjadi tontonan yang begitu besar bagi masyarakat banyak, maka sepakbola dirasa mampu pula menjadi media solidaritas politik bagi suporter sepakbola Indonesia.

\section{TINJAUAN PUSTAKA}

Menurut Arsyad (2002:4) menyebutkan media adalah semua bentuk perantara yang digunakan oleh manusia untuk menyampaikan atau menyebar ide, gagasan atau pendapat, sehingga ide, gagasan atau pendapat yang dikemukakan itu sampai kepada penerima yang dituju.

Media massa adalah saluran komunikasi yang dapat menjangkau khalayak dalam jumlah yang besar, heterogen dan terpencarpencar serta bagi komunikator yang menyebarkan pesannya bersifat abstrak. Media tersebut meliputi televisi, radio, pers, dan film sebagai cirinya yang utama menimbulkan keserempakan dan keserentakan pada khalayak saat diterpa pesan (Effendy, 1992:62). Media massa dalam Kamus Besar Bahasa Indonesia diartikan sebagai alat atau sarana dan saluran komunikasi resmi untuk menyebarkan berita dan pesan kepada masyarakat luas. Sedangkan menurut Soehoet (2003:28) media massa adalah media yang ditujukan kepada khalayak orang, memiliki komunikan lebih dari satu orang, yang satu sama lain umumnya tidak saling mengenal, dan tempat tinggalnya berlainan. Lebih lanjut dijelaskan tentang peran dan fungsi media massa sebagai berikut: 
1) Pengetahuan : menyediakan informasi tentang peristiwa dan kondisi masyarakat dan dunia.

2) Korelasi : menjelaskan, menafsirkan, mengomentari makna dan peristiwa. Menunjang otoritas dan norma-norma yang berlaku, melakukan sosialisasi, mengkoordinasikan kegiatan, membentuk kesepakatan serta menentukan urutan prioritas dan memberikan status relatif.

3) Kesinambungan : mengekspresikan budaya dominan dan mengakui keberadaan khusus serta perkembangan budaya baru dan meningkatkan serta melestarikan nilainilai.

4) Hiburan : menyediakan hiburan, pengalihan perhatian dan sarana relaksasi serta meredakan ketegangan sosial.

5) Mobilisasi : mengkampanyekan tujuan masyarakat dlam bidang politik, perang, ekonomi, dan pekerjaan, juga mengkampanyekan tujuan masyarakat dalam bidang agama

Suatu media dikatakan efektif apabila mendapatkan respon positif dari khalayaknya.Maksudnya pemberian informasi melalui pemakaian atau aplikasi media yang positif dapat menimbulkan efek yang diinginkan sehingga menjadikannya sebagai media informasi yang efektif.Efek atau pengaruh ini telah menjadi pusat perhatian bagi berbagai pihak dalam masyrakat melalui pesan-pesan yang hendak disampaikannya berusaha untuk menjangkau khalayak yang diinginkan. Oleh karenanya, mereka akan berusaha untuk menemukan saluran yang paling efektif untuk dapat mempengaruhi khalayak.

\section{Menurut Kamus Besar Bahasa} Indonesia pengertian kata solidaritas adalah, sifat (perasaan) solider, sifat satu rasa (senasip), perasaan setia kawan yang pada suatu kelompok anggota wajib memilikinya (Depdiknas, 2007:1082). Menurut Kamus Besar Bahasa Indonesia arti kata sosial adalah berkenaan dengan masyarakat, perlu adanya komunikasi dalam usaha menunjang pembangunan, suka memperhatikan kepentingan umum (Depdiknas, 2007:1085).Mengenai solidaritas ini kemudian ditambah menurut Durkheim yang menjelaskan bahwa seluruh anggota masyarakat diikat oleh kesadaran kolektif, hati nurani kolektif yaitu suatu kesadaran bersama yang mencakup keseluruhan kepercayaan dan perasaan kelompok, dan bersifat ekstrim serta memaksa (Kamanto Sunarto, 2004: 128).

Kapasitas sepakbola untuk memobilisasi masa telah terbentuk sejak lama, dikarenakan peran sepakbola sebagai 
salah satu olahraga palimg popular di dunia.Alexander Cardenas (2014:11) pernah menjelaskan bahwa "sepakbola merepresentasikan aktivitas professional, sebuah instrument untuk memobilisasi masa, sebuah bisnis yang menguntungkan, yang juga terfokus pada kekerasan, dan lebih lanjutnya lagi, sepakbola juga bertindak sebagai sebuah alat untuk perkembangan social dan perdamaian". Media cover, sponsor dan akses pada kelompok besar supporter, menyediakan keuntungan bagi banyak orang, termasuk tersampaikannya pesan politik.

Supporter mampu memainkan peran yang besar dalam kegiatan komunikasi politik, sebagai contoh, klub sepakbola Livorno di italia dijelaskan oleh mark Doidge (2013:259) "melalui koreografi pada sebuah pertandingan sepakbola, supporter merepresentasikan afiliasi politik mereka". Selain tumbuh dari latar belakang kelas pekerja saat dikuasasi oleh keluarga medici selama berabad abad, tempat Livorno dalam sejarah pun sudah tertulis sejak tahun 1921 dimana partai komunis italia tumbuh disana.Dengan latar belakang politik yang kuat, merupakan hal yang biasa saat supporter Livorno menampilkan berbagai protes politik untuk meningkatkan kesadaran di stadion.Hal yang sama pun terjadi di spanyol, seperti dijelaskan Spaaij and Viñas (2005:87), "walaupun berbagai macam ideology radikal hadir dan tumbuh pada skena supporter sepakbola sejak awal, sekarang mereka telah tumbuh menjadi sebuah kelompok yang berpengaruh dan membentuk sebuah identitas".

\section{PEMBAHASAN}

Media komunikasi adalah suatu alat atau sarana yang digunakan untuk menyampaikan pesan dari komunikator kepada khalayak atau komunikator pada komunikan. Istilah dari media itu sendiri, di masyarakat terjadi pemahaman yang sempit, media merupakan istilah umum medium atau perantara yang memberi kita informasi mengenai pengetahuan, jadi artian media tidak hanya terbatas pada hal yang sederhana misalnya televisi, radio atau majalah.Media atau medium ini memainkan peran yang berbeda untuk berkomunikasi dengan penerima pesan untuk mengubah presepsi mereka.

Aksi sosial pada ranah sepakbola di seluruh belahan dunia memang sudah sering terjadi. dimana sepakbola mampu menjadi medis solidaritas politik. Sebagai contoh para anggota Green Brigade, pendukung ultras kesebelasan Glasgow Celtic dari liga Skotlandia mengibarkan bendera Palestina saat laga kualifikasi Liga Champions melawan tim asal Israel, Hapoel Be'er Shava, atau yang menarik adalah saat pemain seluruh 
official dari klub sepakbola di liga Yunani, AEL Larissa dan Acharnaikos, melakukan protes terhadap perlakuan yang diterima pengungsi dengan duduk di lapangan selama dua menit sebelum pertandingan dimulai, dan aksi para pemain dari Borussia Dortmund dan FC St. Pauli di liga Jerman yang menyuarakan solidaritas terhadap para pengungsi dengan mengadakan laga persahabatan di markas FC St. Pauli sambal membentangkan spanduk bertuliskan "Refugees Welcome" sebelum kick off.

Solidaritas politik di kalangan masyarakat umum, termasuk juga suportersepakbola muncul dari adanya rasa saling keterhubungan sosial diantara satu orang dengan orang lainnya atau satu kelompok dengan kelompok lainnya.Kasuskasus yang muncul sebagai informasi melalui media dan berhubungan dengan kemanusiaan muncul, juga dikonsumsi sehari-hari oleh banyak orang, termasuk supporter sepakbola di Indonesia. Pesan informasi yang disampaikan oleh media, baik media cetak ataupun media elektronik pada penerima pesan, bisa dengan mudah didapatkan melalui berbagai macam platform digital, mulai dari social media hingga web berita.

Tercatat kasus palestina, mendapatkan perhatian yang cukup besar dari supporter sepakbola Indonesia, tidak hanya satu atau dua supporter dari tim di liga Indonesia menampilkan aksi solidaritas politik, tetapi banyak kelompok supporter melaksanakan aksi serupa. Tercatat Supporter dari tim-tim berikut ini ikut mengeluarkan pesan untuk disampaikan pada khalahyak mengenai kepedulian mereka pada kasus-kasus yang mencoreng kemanusiaan; Persela Lamongan, PSS Sleman, Pusam Borneo, Persebaya Surabaya, Madura United, Persija Jakarta, Persis Solo, Persib Bandung, Persik Kediri dan PSM Makasar.

Beberapa pengaruh yang disimpulkan penulis mengenai solidaritas supporter Indonesia pada beberapa aksi social politik baik dalam dan luar negeri, karena

1. Sejarah politik. Indonesia adalah negara yang sudah mendeklarasikan proklamasi nya pada tanggal 17 Agustus 1945 setelah sebelumnya berada dalam kependudukan Jepang dan Belanda. Dalam Undang-Undang Dasar Negara Republik Indonesia Tahun 1945, atau disingkat UUD 1945 atau UUD '45, yang merupakan hukum dasar tertulis (basic law), konstitusi pemerintahan negara Republik Indonesia saat inimenyebutkan bahwa "Bahwa sesungguhnya kemerdekaan itu adalah hak segala bangsa dan oleh sebab itu maka penjajahan di atas dunia harus dihapuskan karena tidak sesuai dengan peri kemanusiaan dan peri keadilan". Menyatakan bahwa negara Indonesia selain tidak mendukung berbagai jenis penjajahan diatas dunia, juga PSSI 
sebagai federasi sepakbola resmi di Indonesia juga hadir atas dasar perlawanan terhadap kependudukan bangsa penjajah.

2. Sepakbola Indonesia. PSSI adalah federasi resmi sepakbola di Indonesia dibentuk pada tanggal 19 April 1930 di Yogyakarta dan sebagai sebuah organisasi olahraga yang lahir pada masa penjajahan Belanda, tentu saja memiliki kaitan dengan upaya politik untuk menentang penjajahan. PSSI lahir dari sebuah muatan politis, baik secara langsung maupun tidak, untuk menentang penjajahan dengan strategi menyemai benih-benih nasionalisme di dada pemuda-pemuda Indonesia. Latar belakang sepakbola di Indonesia ini memiliki,

3. Negara berpenduduk muslim terbesar adalah faktor penting dan solidaritas pada palestina atau rohingya adalah hal wajar dikarenakan persamaan latar belakang kepercayaan. Indonesia pernah berdiplomasi untuk meminta dukungan dari negara-negara lain selama perjuangan kemerdekaan, dan salah satu dukungan yang paling besar datang dari dua negara Timur Tengah, yaitu Palestina dan Mesir.

4. Organisasi internasional, pada hal ini Indonesia dan Myanmar, sama-sama merupakan negara anggota organisasi internasional ASEAN, yang mana adalah sebuah organisasi kawasan negara-negara yang berada di kawasan Asia Tenggara, ASEAN bentuk pada tahun 1967 oleh Indonesia, Malaysia, Filipina, Singapura, dan Thailand untuk mempromosikan kerjasama politik dan ekonomi dan stabilitas regional. Brunei bergabung pada tahun
1984, tak lama setelah kemerdekaannya dari Inggris, dan Vietnam bergabung ASEAN sebagai anggota ketujuh pada tahun 1995.Laos dan Myanmar yang mengakui ke keanggotaan penuh pada bulan Juli 1997 sebagai ASEAN merayakan ulang tahun ke-30. Kamboja menjadi anggota kesepuluh ASEAN pada tahun 1999. Begitu pula, Indonesia dengan Palestina,keduanya merupakan anggota gerakan negara Non-blok. Gerakan Non-Blok sendiri merupakan sebuah gerakan yang bermula dari Konferensi Tingkat Tinggi AsiaAfrika (KAA) sebuah konferensi yang diadakan di Bandung, Indonesia, pada tahun 1955. Di sana, negara-negara yang tidak berpihak pada blok tertentu mendeklarasikan keinginan mereka untuk tidak terlibat dalam konfrontasi ideologi Barat-Timur.

5. Pengaruh pemimpin kelompok supporter. Peranan pimpinan dalam suatu organisasi, organisasi apapun itu, termasuk organisasi supporter, sangatlah penting karena keberadaan pimpinan yaitu menjadi palang pintu atau menjadi salah satu ujung tombak dari keberhasilan dalam sebuah organisasi.Visi supporter yang tertuang pada solidaritas adalah pernyataan yang secara relatif mendeskripsikan aspirasi atau arahan untuk masa depan organisasi.

Kelima efek tersebut merupakan alasan yang kemudian membentuk sikap supporter Indonesia dalam menghadapi fenomena politik kasus Palestina dan Rohingya. Sepakbola yang merupakan pertandingan 
popular yang ditonton oleh banyak masyarakat Indonesia, diharapkan mampu menjadi media penyampaian informasi akan sikap yang dihadirkan banyak supporter Indonesia. Menurut berita dari beritagar.id (https://beritagar.id/artikel/arena/jumlahpenonton-liga-1-capai-12-juta-orang), jumlah penonton saat laga dihelat malam pada fase Ramadhan pun animo penonton naik $1,7 \%$. Dalam 19 hari sepanjang Juni 2017 terserap 256.512 penonton. Pasca Lebaran, hingga pekan ketiga Juli 2017, sudah 299.695 penonton tersedot. Total, per 21 Juli 2017, liga yang diikuti 18 klub ini mampu memagnet 1.213.805 penonton.

\section{KESIMPULAN}

Sepakbola pada akhirnya bukan hanya pertandingan $2 \times 45$ menit di lapangan hijau, pemahaman mengenai sepakbola pun bertambah, tidak hanya sebatas taktik dan strategi atau menariknya permainan di lapangan. Sepakbola bisa menjadi alat sosial politis yang sangat berguna yaitu sebagai medium pemersatu, menjadi penghantar pesan atau informasi mengenai perdamaian untuk disampaikan pada khalayak luas. Peristiwa sosial politis yang terjadi di banyak belahan dunia, menjadi salah satu trigger mengapa sepakbola mampu muncul sebagai suatu alat solidaritas politik, sebagai pengingat pada khalayak bahwa penonton sepakbola bisa menyampaikan pesan solidaritas. Dalam kajian komunikasi, suporter bertindak sebagai komunikator, media yang digunakan sepakbola, pesan yang disampaikan adalah bentuk solidaritas, penonton pertandingan sepakbola adalah penerima pesan, dan pesan dikenal khalayak adalah suatu bentuk feedback.

Dalam kajian ilmu komunikasi peran supporter Indonesia pada kasus Palestina dan Rohingya menjadi salah satu proses komunikasi yang terlihat jelas, dimana ke lima unsur komunikasi, seperti komunikator, pesan, media komunikasi, komunikan dan feedback semuanya nampak. Supporter menyampaikan pesan berupa dukungan pada warga Palestina dan Rohingya melalui media komunikasi, dimana media komunikasi tersebut adalah sepakbola, yang berperan menjadi media massa, yang merupakan media komunikasi yang digunakan untuk mengkomunikasikan pesan kepada masyarakat luas, dan akhirnya feedback yang terjadi adalah pesan solidaritas yang disampaikan diterima oleh masyarakat Palestina dan Rohingya. 


\section{Daftar pustaka}

Effendy, Onong Uchjana, Komunikasi Teoridan Praktek, Bandung: Remaja Pengantar Ilmu Komunikasi, Jakarta : Grasindo. Rosdakarya

Effendy, Onong Uchjana. 1992. Humas Suatu Studi Komunikologis PT.Remaja Rosda, Bandung

Arsyad (2002)."Karakteristik Media Pembelajaran".Jakarta PT Raja Garfindo Perasada.

Soehoet, A.M. Hoeta, 2003. Pengantar Ilmu Komunikasi. Cetakan Kedua. Jakarta: yayasan Kampus Tercinta IISIP.

Alwi, Hasan. 2007. Kamus Besar Bahasa Indonesia. Balai Pustaka: Jakarta.

Sunarto, Kamanto. (2004). Pengantar Sosiologi (edisi ketiga). Jakarta : Lembaga Penerbit Fakultas Ekonomi, Universitas Indonesia.

Doidge Mark, 2013, 'The birthplace of Italian communism': political identity and action amongst Livorno fans, Soccer \& Society, 14:2, 246-261.

Spaaij Ramón, ViñasCarles, 2005, Passion, politics and violence: A sociohistorical analysis of Spanish ultras, Soccer \& Society, 6:1, 79-96

Cárdenas Alexander, 2014, The Global Journey of Football: From the origins of the beautiful game to its recent use as a social catalyst, Hamburg, Anchor Academic Publishing 2014. 